\title{
Glyoxal-Lysine Dimer, an Advanced Glycation End Product, Induces Oxidative Damage and Inflammatory Response by Interacting with RAGE
}

\author{
Hee-Weon Lee ${ }^{1}$, Min Ji Gu ${ }^{1}$, Yoonsook Kim ${ }^{1}$, Jee-Young Lee ${ }^{2} \mathbb{D}$, Seungju Lee ${ }^{2} \mathbb{D}$, In-Wook Choi ${ }^{1}$ \\ and Sang Keun $\mathrm{Ha}{ }^{1,3, *(D)}$ \\ 1 Korea Food Research Institute, 245, Nongsaengmyeong-ro, Iseo-myeon, \\ Wanju-gun 55365, Jeollabuk-do, Korea; 07989@kfri.re.kr (H.-W.L.); 50032@kfri.re.kr (M.J.G.); \\ kimyus@kfri.re.kr (Y.K.); choiw@kfri.re.kr (I.-W.C.) \\ 2 Molecular Design Team, New Drug Development Center, Daegu Gyeongbuk Medical Innovation \\ Foundation (DGMIF), Daegu 41061, Korea; jyoung@dgmif.re.kr (J.-Y.L.); sjlee05@dgmif.re.kr (S.L.) \\ 3 Division of Food Biotechnology, University of Science and Technology, Daejeon 34113, Korea \\ * Correspondence: skha@kfri.re.kr; Tel.: +82-63-219-9358
}

check for

updates

Citation: Lee, H.-W.; Gu, M.J.; Kim, Y.; Lee, J.-Y.; Lee, S.; Choi, I.-W.; Ha, S.K. Glyoxal-Lysine Dimer, an Advanced Glycation End Product, Induces Oxidative Damage and Inflammatory Response by Interacting with RAGE. Antioxidants 2021, 10, 1486. https://doi.org/10.3390/ antiox10091486

Academic Editor: Cinzia Antognelli

Received: 9 August 2021

Accepted: 14 September 2021

Published: 17 September 2021

Publisher's Note: MDPI stays neutral with regard to jurisdictional claims in published maps and institutional affiliations.

Copyright: (c) 2021 by the authors. Licensee MDPI, Basel, Switzerland. This article is an open access article distributed under the terms and conditions of the Creative Commons Attribution (CC BY) license (https:/ / creativecommons.org/licenses/by/ $4.0 /)$.

\begin{abstract}
The glyoxal-lysine dimer (GOLD), which is a glyoxal (GO)-derived advanced glycation end product (AGE), is produced by the glycation reaction. In this study, we evaluated the effect of GOLD on the oxidative damage and inflammatory response in SV40 MES 13 mesangial cells. GOLD significantly increased the linkage with the V-type immunoglobulin domain of RAGE, a specific receptor of AGE. We found that GOLD treatment increased RAGE expression and reactive oxygen species (ROS) production in mesangial cells. GOLD remarkably regulated the protein and mRNA expression of nuclear factor erythroid 2-related factor 2 (NRF2) and glyoxalase 1 (GLO1). In addition, mitochondrial deterioration and inflammation occurred via GOLD-induced oxidative stress in mesangial cells. GOLD regulated the mitogen-activated protein kinase (MAPK) and the release of proinflammatory cytokines associated with the inflammatory mechanism of mesangial cells. Furthermore, oxidative stress and inflammatory responses triggered by GOLD were suppressed through RAGE inhibition using RAGE siRNA. These results demonstrate that the interaction of GOLD and RAGE plays an important role in the function of mesangial cells.
\end{abstract}

Keywords: glyoxal-lysine dimer; advanced glycation end product; receptor of advanced glycation end product; oxidative stress; NRF2/GLO-1; mitochondrial function

\section{Introduction}

Advanced glycation end products (AGEs) are stable proteins with post-translational modifications formed through spontaneous reactions with glucose and metabolite such as glyoxal and methylglyoxal. They are a large, heterogeneous group of compounds resulting from nonenzymatic Maillard reactions between reducing sugars and proteins, lipids, or nucleic acids, which can be produced both in vitro and in vivo [1,2]. AGEs contribute to the development of cancer and many chronic diseases, including diabetes and diabetic complications and neurodegenerative, cardiovascular, and kidney diseases [3-5]. AGEs, compounds formed by non-enzymatic reactions, can be obtained exogenously through food or formed endogenously in the body [6]. The effect of AGE consumption on the development of chronic diseases has remained inconclusive. Several systematic reviews of recent animal and clinical trials have shown that ingestion of AGEs may increase risk factors associated with chronic conditions, such as chronic renal disorder, oxidative stress, and a diabetic environment $[7,8]$. In addition, previous studies have shown the effect of an inflammatory response and oxidative stress after AGE consumption between healthy and diseased conditions. $[9,10]$. AGEs have a significant impact on the development and development of kidney damage. 
Various AGEs contribute to the development of chronic kidney disease and cause diverse kidney failures. The production of AGEs further increases the concentration of AGEs associated with chemical and structural kidney changes, leading to nephropathy [11,12]. Besides, the formation and accumulation of AGEs initiate an even more serious pathogenic relationship with nephropathy in diabetes. The receptor for AGEs (RAGE) is a multi-ligand receptor of the immunoglobulin superfamily of cell surface molecules that act as receptors for a variety of molecules [13]. The participation of RAGE leads to the transmission of signals that cause cell dysfunction and tissue destruction. Indeed, AGE-induced kidney damage is more severe in patients with diabetes. Therefore, research related to the AGE receptor for AGE in renal dysfunction has focused on diabetes. However, besides the serious effect on the kidneys under diabetes, AGE-RAGE is implicated in kidney complications associated with obesity, inflammation, and high blood pressure $[9,14,15]$.

AGE-specific receptors are expressed on various cells and affect the regulation of AGE uptake and removal as well as cell activation. As a key receptor for AGEs, RAGE is a multiligand receptor present in various organs that crucially influences the inflammatory process. It accumulates in various tissues due to oxidative stress induced by AGE accumulation. The generation of these signals through the combination of AGEs and RAGE causes various diseases and processes, such as kidney disease, cancer, diabetes, vascular disease, and aging $[12,16,17]$. Normally, the expression of RAGE is low in normal tissues but can be very high under pathological conditions, as mentioned earlier. Moreover, the combination of RAGE and RAGE ligands increases the expression of RAGE in various cells. This positive feedback loop may partially explain why RAGE-ligand interactions can trigger sustained activation of the RAGE downstream pathway $[13,18]$. Thus, the interaction between AGEs and RAGE is a key factor in the generation and exacerbation of lesions. Furthermore, the AGE-RAGE interaction triggers intracellular signaling that attenuate the nuclear factor erythroid 2-related factor 2 (NRF2) in a consistent cellular response. Besides, during this interaction, energy metabolism is affected via mitochondrial impairment [19].

Previous studies have shown that mitochondrial dysfunction via the AGE-RAGE axis is important for kidney lesion development. Oxidative stress-induced damage is the result of an imbalance between reactive oxygen species (ROS) production and detoxification and is directly linked to mitochondrial dysfunction. In addition, oxidative stress due to mitochondrial dysfunction affects kidney disease through excessive inflammatory reactions $[11,20]$. Several studies have shown that oxidative stress-triggered mitochondrial dysfunction occurs in inflammatory diseases, being key in kidney disease. Furthermore, the activity of the AGE-RAGE axis essentially affects the induction of ROS production in lesion development and progress [9]. However, the association between oxidative stress and AGE-mediated ROS as well as the mitochondrial dysfunction caused by this process remains unclear.

Abnormal ROS generation disrupts mitochondrial function and alters genetic mechanisms, triggering cellular damage. NRF2 is a key transcription factor that regulates genes involved in the antioxidant defense system. The expression of homeostasis regulators such as glyoxalase 1 (GLO1), which are regulated by NRF2, plays a role in preventing renal lesions from excessive inflammatory reactions through antioxidant reactions in mesangial cells [21]. NRF2 remains inactive while binding to Kelch-like ECH-associated protein 1 (KEAP1) in the cytoplasm [19]. Under an oxidative stress environment, the active site cysteine residue of KEAP1 is oxidized, preventing KEAP1 from interacting with NRF2. NRF2 then moves to the nucleus and activates the target gene through an antioxidant response element, which suppresses oxidative stress [22].

Excessive production of ROS and mitochondrial dysfunction play an important role in AGE-RAGE-mediated kidney disease. In addition, the oxidative stress reaction that occurs in this process is regulated by the NRF2/GLO1 signaling pathway [23,24]. The purpose of this study was to investigate the oxidative stress and inflammatory response by GOLD in mesangial cells. Our findings show that the interaction of GOLD and RAGE is related 
to oxidative stress and inflammatory responses in mesangial cells. We believe that these results will be helpful in the study of the effect of GOLD on kidney mesangial cells.

\section{Materials and Methods}

\subsection{Chemical Reagents and Antibodies}

Glyoxal-lysine dimer (GOLD) was purchased from IRIS Biotech GMBH (Marktredwitz, Germany). DMEM/Nutrient Mixture F-12 (DMEM/F12) and fetal bovine serum (FBS) were purchased from Lonza (Basel, Switzerland). Propidium iodide (PI), 4',6-diamidino2-phenylindole (DAPI), and 2', $7^{\prime}$-dichlorodihydrofluorescein diacetate (DCF-DA) were purchased from Sigma-Aldrich (St. Louis, MO, USA). The tetraethylbenzimidazolylcarbocyanine iodide (JC-1) mitochondrial membrane potential (MMP) assay kit was purchased from Abcam (Cambridge, UK). Antibodies against target molecules were obtained from Cell Signaling (Danvers, MA, USA), unless otherwise stated.

\subsection{Cell Culture}

The murine mesangial cell line SV40 MES 13 was purchased from ATCC (Rockville, MD, USA). SV40 MES 13 cells were cultured in DMEM/F12 supplemented with $2 \mathrm{mM}$ L-glutamine, $100 \mathrm{IU} / \mathrm{mL}$ penicillin, $100 \mu \mathrm{g} / \mathrm{mL}$ streptomycin, $14 \mathrm{mM} \mathrm{HEPES}$, and $5 \%$ heatinactivated FBS. SV40 MES 13 cells were then incubated in a fully humidified incubator at $37{ }^{\circ} \mathrm{C}$ with $5 \% \mathrm{CO}_{2}$. SV40 MES 13 cells were maintained in the culture medium at a concentration of $500 \mu \mathrm{M}$ for $24 \mathrm{~h}$.

\subsection{Measurement of ROS}

ROS production was quantified under fluorescence microscopy (ZEISS, Oberkochen, Germany) using a DCF-DA probe. In addition, we conducted an experiment using the antioxidant, $\mathrm{N}$-Acetyl-L-cysteine (NAC). Mouse mesangial cells were incubated with $10 \mu \mathrm{M}$ DCF-DA in the dark for $30 \mathrm{~min}$ at $37^{\circ} \mathrm{C}$, rinsed with phosphate-buffered saline (PBS), and counted using an ELISA plate reader (Molecular Devices, CA, USA). The following settings were used: Excitation, $488 \mathrm{~nm}$ and emission, $522 \mathrm{~nm}$.

\subsection{Docking Study}

The GOLD-binding site in RAGE is the same as that of the methylglyoxal-lysine dimer (GOLD), as demonstrated in a previous article [25]. The binding model between GOLD and RAGE was predicted by docking simulation, and the final model was suggested using Molecular Mechanics energies combined with the Generalized Born and Surface Area (MM-GBSA) calculation. All calculations were performed using Glide and Prime modules of MAESTRO (Schrödinger LLC, New York, NY, USA) in a Linux environment with default parameters [26].

\subsection{MitoTracker Staining and Confocal Laser Microscopy}

MitoTracker Orange CMTMRos (Invitrogen, Carlsbad, CA, USA), a mitochondriaspecific cationic fluorescent dye, was used to label the mitochondria. Transfected SV40 MES 13 cells were incubated with $200 \mathrm{nM}$ MitoTracker for $1 \mathrm{~h}$ at $37^{\circ} \mathrm{C}$ and washed four times with heated PBS. Cells were imaged using a confocal laser scanning microscope (ZEISS).

\subsection{Immunofluorescence Assay}

The expression of AGEs, RAGE, NRF2, and mitochondrial genes in GOLD-stimulated mesangial cells was determined under fluorescence microscopy. SV40 MES 13 cells were cultured on glass coverslips ( $22 \mathrm{~mm}$ in diameter) at a density of $2 \times 10^{4}$ cells and then incubated with GOLD $(500 \mu \mathrm{M})$ for $2 \mathrm{~h}$. Mesangial cells were rinsed with PBS and fixed with $3.7 \%$ formaldehyde in PBS for $30 \mathrm{~min}$ at $20-22{ }^{\circ} \mathrm{C}$. They were permeabilized with $0.2 \%$ Triton X-100 in PBS for $1 \mathrm{~h}$. Thereafter, they were washed in PBS and incubated with antibodies against AGEs, RAGE, NRF2, GLO-1, DRP1, or MFN1 overnight at $4{ }^{\circ} \mathrm{C}$. After washing with PBS, cells were incubated for $1 \mathrm{~h}$ with fluorescein isothiocyanate 
(FITC)-conjugated anti-rabbit IgG in $0.2 \%$ Triton X-100 in PBS. Cells were rinsed thoroughly, mounted with glycerol:PBS (4:1), and photographed using an LSM 900 fluorescence microscope (ZEISS).

\subsection{RNA Extraction and Reverse Transcription-Polymerase Chain Reaction (RT-PCR)}

The mRNA expressions of several genes were measured by qRT-PCR. After GOLD treatment, total RNA was isolated from cultured cells using Trizol (Sigma, St. Louis, MO, USA), according to the manufacturer's instructions, and used for cDNA synthesis. qRTPCR was performed using specific primers (Table 1). cDNA was amplified in $20 \mu \mathrm{L}$ of a PCR reaction mixture $(1 \mu \mathrm{L}$ each of forward and reverse primers, $8 \mu \mathrm{L}$ of cDNA synthesis solution in pure water, and $10 \mu \mathrm{L}$ of SYBR Green Master Mix) in a quantitative real-time PCR system. Fluorescence was measured at each cycle.

Table 1. Primer sequences for real-time PCR.

\begin{tabular}{|c|c|c|}
\hline Gene & Forward Primer $\left(5^{\prime} \rightarrow 3^{\prime}\right)$ & Reverse Primer $\left(5^{\prime} \rightarrow 3^{\prime}\right)$ \\
\hline RAGE & AAG CCC CTG GTG CCT AAT GAG & GAA TTC ATG GCA GAG CCA CAG CCG \\
\hline NRF2 & ATA TTC CCA GCC ACG TTG AG & AAC TTG CTC CAT GTC CTG CT \\
\hline GLO1 & GAA TTC ATG GCA GAG CCA CAG CCG & GAA TTC ATG GCA GAG CCA CAG CCG \\
\hline GAPDH & TGC ATC CTG CAC CAC CAA & TCC ACG ATG CCA AAG TTG TC \\
\hline
\end{tabular}

\subsection{Immunoblotting}

SV40 MES 13 cells were seeded into $60 \mathrm{~mm}$ cell culture plates at a density of $2 \times 10^{6}$ cells/well and incubated with GOLD $(500 \mu \mathrm{M})$. After treatment, cultured cells were rinsed with PBS and suspended in a homogenized lysis buffer. The supernatant was collected after centrifugation for $5 \mathrm{~min}$ at $12,000 \times g$ and $4{ }^{\circ} \mathrm{C}$. The protein concentration was determined using a DC protein assay kit (Bio-Rad, Hercules, CA, USA), with BSA as the standard. Whole-cell lysates were separated using 6-15\% SDS-PAGE and transferred to a nitrocellulose membrane (Bio-Rad Laboratories, Hercules, CA, USA). Membranes were blocked with 5\% skim milk in Tris-buffered saline containing $0.2 \%$ Tween 20 at $20-22{ }^{\circ} \mathrm{C}$ for $1 \mathrm{~h}$ and probed with the appropriate primary (1:500) and secondary (1:5000) antibodies. Blots were developed using an enhanced chemiluminescence kit. In each experiment, the density ratio represents the relative intensity of each band normalized to that of $\beta$-actin as a control. The following antibodies were used: Phospho-ERK (\#9101), ERK (\#9102), phospho-JNK (\#9258), JNK (\#9251), phospho-p38 (\#4551), p38 (\#8690), and NRF2 (\#12721), all from Cell Signaling Technologies (Danvers, MA, USA); TNF- $\alpha$ (sc12744), IL-6 (sc32296), IL-1 $\beta$ (sc12742), OPA1 (sc393296), Mfn1 (sc16664), and Drp1 (sc271583), all from Santa Cruz Biotechnology, (Dallas, TX, USA), RAGE (ab216329); IL-18 (ab74495), p21 (ab188224), p27 (ab32034), CDK2 (ab32147), and GLO-1 (ab171121), all from abcam (Cambridge, UK); and AGEs (bs1158R), all from BIOSS (Woburn, MA, USA).

\subsection{RNA Interference}

SV40 MES13 cells were plated into 6-well culture plates and transiently transfected with RAGE small interfering RNA (siRNA) (Santa Cruz, CA, USA) mixed with an siRNA transfection reagent (Invitrogen Biotechnology, Carlsbad, CA, USA), according to the manufacturer's instructions. To knockdown endogenous RAGE, cells were transiently transfected with siRNA at a concentration of $50 \mathrm{nM}$ for $20 \mathrm{~h}$.

\subsection{Assessment of Mitochondrial Transmembrane Potential ( $\triangle \Psi m$ ), Biogenesis, AGEs, and ATP Production}

Mitochondrial membrane potential (MMP) was measured by staining mesangial cells with JC-1, a cationic dye that accumulates in energized mitochondria. The JC-1 solution $(20 \mu \mathrm{M})$ was added to each dish 30 min prior to the end of the treatment, and then cells 
were rinsed with dilution buffer. Fluorescence images were captured under an LSM 900 fluorescence microscope.

Cells were fixed with fixing solution and stimulated with quenching buffer for mitobiogenesis at room temperature. The cultured cells were incubated with blocking buffer at $37^{\circ} \mathrm{C}$. After reacting the prepared primary antibody in all wells, the secondary antibody was incubated at room temperature. Cells had HRP One-Step Substrate Reagent added to each well, they were incubated at room temperature, and checked by adding a stop solution.

Total AGEs levels were investigated using enzyme-linked immunosorbent assay (ELISA) kits (Cell Biolabs, Inc., Beverly, MA, USA) according to the manufacturer's instructions, and the results were normalized to total protein concentrations. The total AGE amount was measured using a microplate reader at $450 \mathrm{~nm}$.

SV40 MES 13 cells were seeded into 96-well black microplates at a density of $2 \times 10^{4}$ cells/well for ATP production. The culture medium was removed, the ATP incubation medium (KCL $15 \mathrm{mM}$, Tris- $\mathrm{HCl} 25 \mathrm{mM}$, EDTA $0.2 \mathrm{mM}, \mathrm{KH}_{2} \mathrm{PO}_{4} 1 \mathrm{mM}, \mathrm{pH} 7.4,1 \%$ albumin, ADP $1 \mathrm{mM}$ ) and malate $100 \mathrm{mM}$ was added, and the cells were incubated at $37^{\circ} \mathrm{C}$ for $2 \mathrm{~h}$. After the incubation medium was withdrawn and cells were washed with PBS, the incubation medium without ADP was added, and the cells were detached with a cell scraper. The cell supernatant was collected in a micro test tube, boiled with Tris-EDTA, and centrifuged at $1000 \times g$ at room temperature for $1 \mathrm{~min}$. The supernatant was then collected for protein and ATP assay. Samples were placed in a 96-well plate (Corning Inc., Corning, NY, USA), and BSA protein (Sigma, St. Louis, MO, USA) with a series concentration $(0-0.2 \mathrm{mg} / \mathrm{mL})$ was utilized as the standard to normalize the assay. Optical absorption at $595 \mathrm{~nm}$ was measured. The quantity of ATP was measured using an ATP determination kit (A-22066, Eugene, OR, USA) following the manufacturer's instructions. The reagents and reaction mixture were combined according to the protocol by molecular probes.

\subsection{Flow Cytometry}

Cell cycle progression was determined using flow cytometry. Mesangial cells were incubated with GOLD for $2 \mathrm{~h}$, collected, and fixed with $4 \%$ formaldehyde at $4{ }^{\circ} \mathrm{C}$ overnight. After removal of the fixing buffer, cells were stained with $50 \mu \mathrm{g} / \mathrm{mL}$ PI solution containing RNase A $(10 \mu \mathrm{g} / \mathrm{mL})$ for $1 \mathrm{~h}$ in the dark. Fluorescence-activated cell sorting analysis was conducted on a CytoFLEX S Flow Cytometer, and data analysis was performed using Kaluza Analysis Software (Beckman Coulter, Indianapolis, IN, USA).

\subsection{Statistical Analyses}

For each experiment, data were obtained in triplicate and reported as the mean $\pm \mathrm{SEM}$. Comparisons of means between GOLD-treated cells and untreated control cells were conducted using analysis of variance and Student's $t$-test. Significant differences were considered at $p<0.05$.

\section{Results}

\subsection{Effects of GOLD on AGEs and RAGE Levels}

AGE accumulation in the body can cause several serious disorders. Currently, RAGE is considered a key factor that transmits AGE signals. Various lesions are known to be exacerbated through several signaling processes via RAGE. Therefore, we determined the formation of AGEs and RAGE expression in the presence of GOLD. Besides, we investigated the association between AGE formation and RAGE distribution in mesangial cells. As shown in Figure 1A,B, when GOLD was added, AGEs were detected not only intracellularly but also extracellularly. We confirmed that the protein and mRNA levels of RAGE increased with AGE production (Figure 1C,D). In addition, immunofluorescence analysis revealed that GOLD induced the expression of RAGE and its translocation to the cell membrane in SV40 MES 13 cells (Figure 1E). Collectively, these findings demonstrate that GOLD induces AGE levels and RAGE expression compared with untreated cells. 


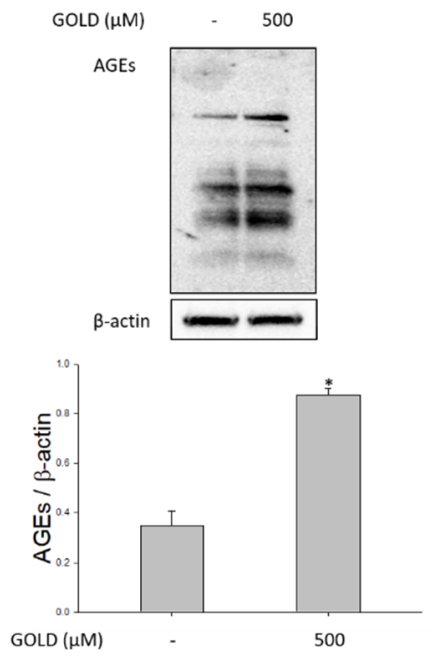

(A)

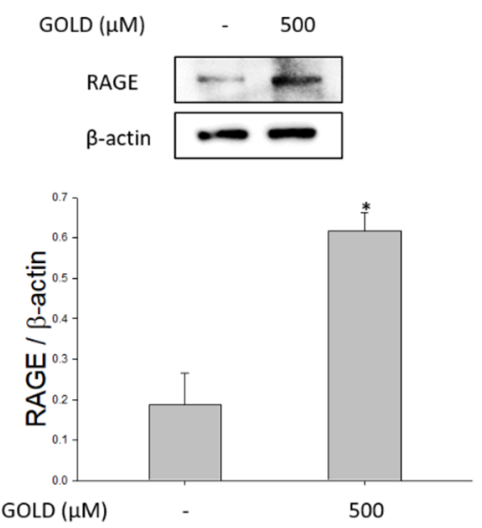

(C)

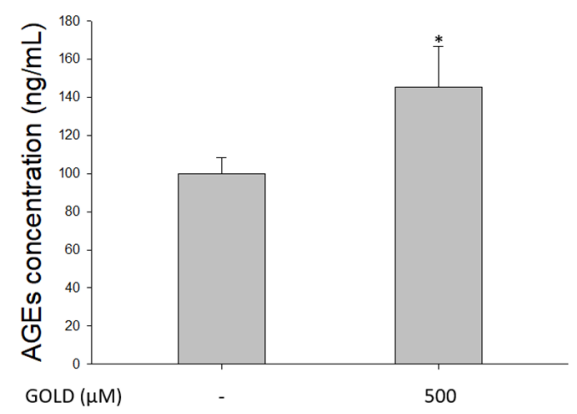

(B)

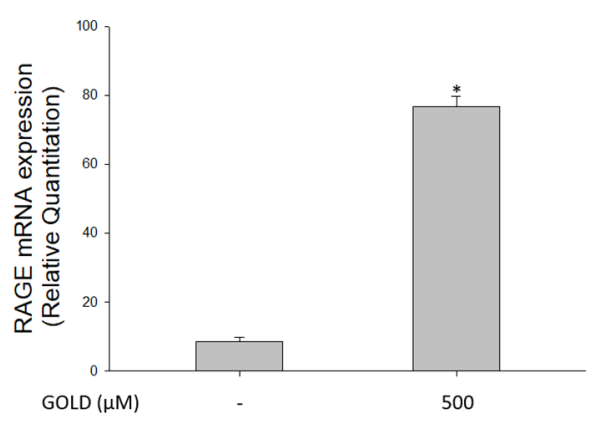

(D)

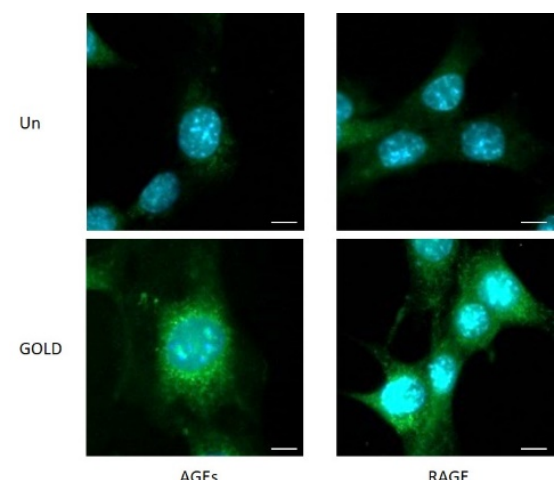

(E)

Figure 1. Effects of advanced glycation end products (AGEs) and expression of receptor for AGEs (RAGE) levels. SV40 MES 13 cells were stimulated with the glyoxal-lysine dimer (GOLD; $500 \mu \mathrm{M})$ for $24 \mathrm{~h}$. (A,C) The protein levels of AGEs and RAGE were determined using Western blotting, with $\beta$-actin as an internal control. (B) AGE production was measured using an ELISA kit (CELL BIOLABS, STA-817). (D) RAGE expression was determined using RT-qPCR. GAPDH was used as an internal control. (E) SV40 MES 13 cells were incubated with a vehicle (medium) or GOLD for $24 \mathrm{~h}$. After stimulation, cells were treated with anti-AGE and -RAGE primary antibodies, followed by fluorescein isothiocyanate (FITC)-labeled anti-rabbit IgG. Cells were detected using fluorescence microscopy at $\times 400$ magnification. Scale bar, $20 \mu \mathrm{m}$. Data are expressed as the mean $\pm \mathrm{SEM}$ of three independent experiments. ${ }^{*} p<0.05$ indicates a significant difference compared to the untreated group. 


\subsection{Prediction of Binding Model between GOLD and RAGE}

The AGE-RAGE axis is a key mechanism in kidney disorders. To examine whether the stimulatory effect of GOLD on this receptor is related to the structural interaction as well as RAGE expression, the structural binding between GOLD and RAGE was evaluated in mesangial cells. It is known that several RAGE ligands, such as methylglyoxal-derived hydroimidazolone-1 (MG-H1) and GOLD, bind to the V domain of RAGE $[25,27,28]$. The binding site of AGEs in RAGE comprises several positively charged residues, such as Lys and Arg, and these residues formed an H-bond interaction with GOLD (Figure 2B,C). The final binding model of GOLD and RAGE is depicted in Figure 2D,E. The amine group of GOLD participated in the hydrogen bond with the backbone carbonyl group of Arg98 and side chain carbonyl of Gln80. The carboxyl acid of the imidazole ring formed an H-bond with Arg114. The key feature of the binding of GOLD to RAGE is the H-bond interactions with amino acid residues. An H-bond interaction is a major feature that determines the specificity of ligand binding to the target protein [29]. It was confirmed that the Lys moiety of GOLD contributes to its stable binding by forming hydrogen bonds with amino acid residues of RAGE.

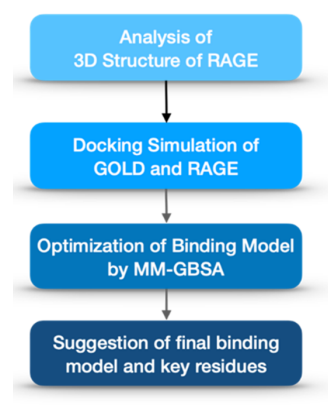

(A)

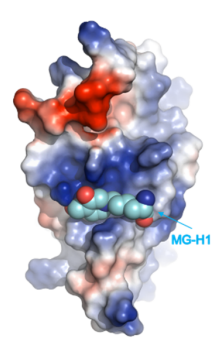

(C)

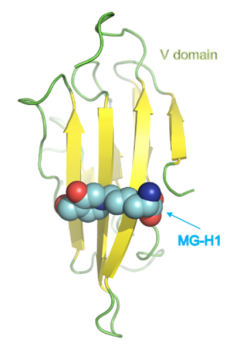

(B)

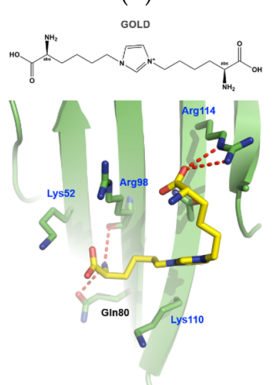

(D)

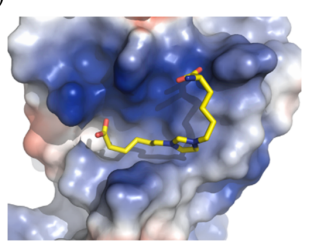

(E)

Figure 2. Prediction of the binding model between the glyoxal-lysine dimer (GOLD) and RAGE. Signaling in the mechanisms of GOLD treatment was investigated. Mesangial cells were stimulated with GOLD $(500 \mu \mathrm{M})$ for $24 \mathrm{~h}$. (A) Steps of the docking simulation to determine the binding model of GOLD and RAGE (B) Binding structure of the V domain of RAGE and the known ligand methylglyoxal-derived hydroimidazolone-1 (MG-H1) according to nuclear magnetic resonance (NMR) (2MOV.pdb). (C) Electrostatic surface model of the V domain of RAGE. (D) Binding model of GOLD and the V domain of RAGE according to the docking simulation. The red dashed line represents the H-bond. (E) Electrostatic surface model of GOLD and RAGE. Blue indicates the positively charged region, and red indicates the negatively charged region. There are many positively charged residues (colored blue) around the GOLD-binding site. 


\subsection{Effects of GOLD on Inflammatory Mediators, ROS Production, and Cell Cycle}

It is well known that the AGE-RAGE axis causes excessive ROS production of cells in many diseases. In addition, these ROS are closely related to cell damage through oxidative stress. As shown in Figure 3A,B, we determined the effect of GOLD on ROS production using an ELISA reader and confocal microscopy. Treatment with $500 \mu \mathrm{M}$ GOLD increased ROS production by approximately 3.7 -fold compared with that in the untreated group. We used the antioxidant NAC to determine the effect of ROS. Treatment with NAC reduced the production of ROS by more than $50 \%$. This indicates that the binding of GOLD to RAGE is associated with inflammatory responses through ROS production in mesangial cells. ROS is key to oxidative stress and is an important component of the signaling system through direct interaction with RAGE. Therefore, we performed fluorescence staining to investigate the relationship between the AGE-RAGE axis and ROS production by GOLD stimulation, which is important for the oxidative stress response. Immunofluorescence analysis revealed that the distribution of RAGE, according to AGE stimulation, and ROS generated along the AGE-RAGE axis interact in mesangial cells (Figure 3C).

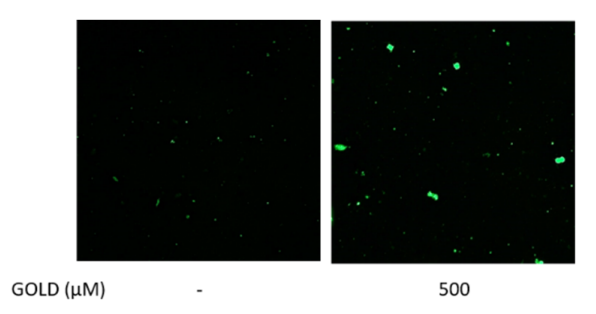

(A)

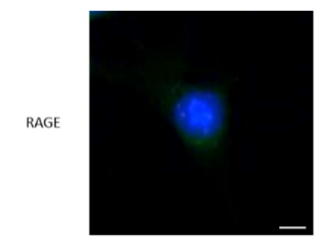

GOL $(\mu \mathrm{M})$

NAC

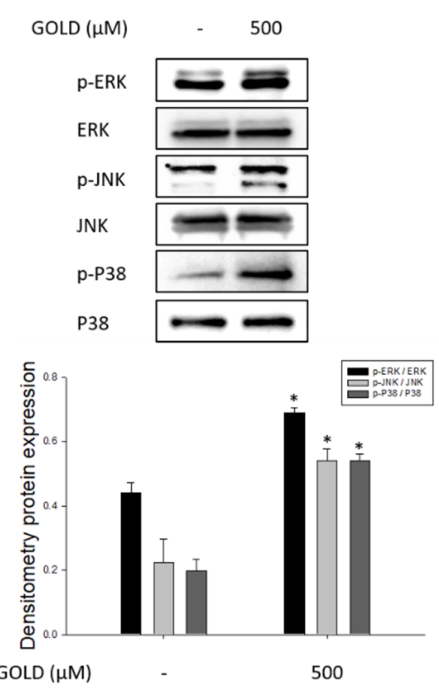

(D)

500

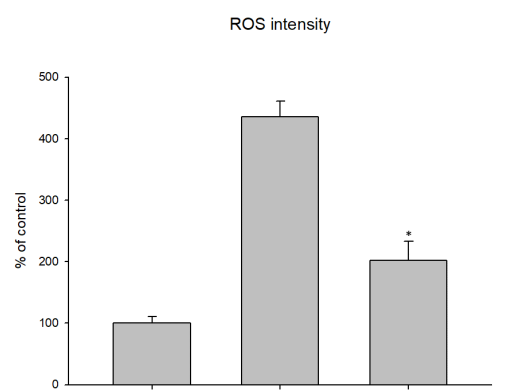

(B)

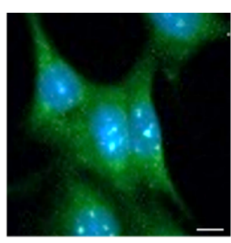

(C)
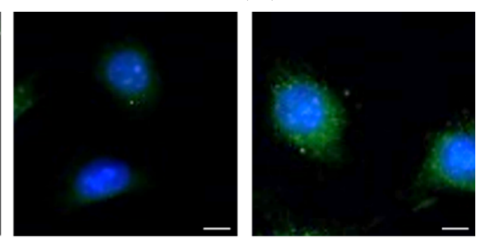

500
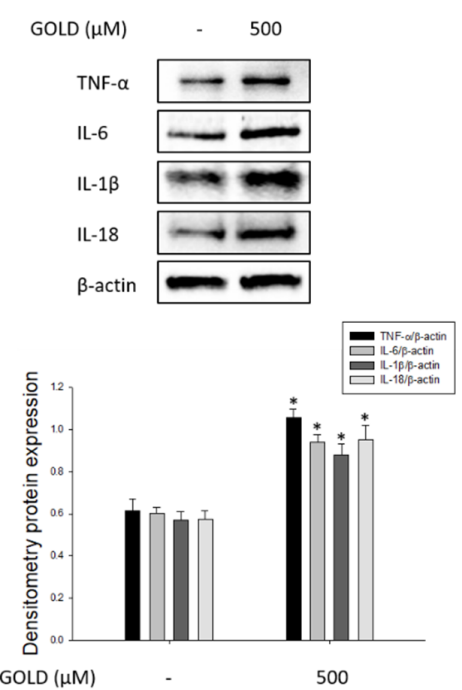

$(\mathbf{E})$

Figure 3. Cont. 


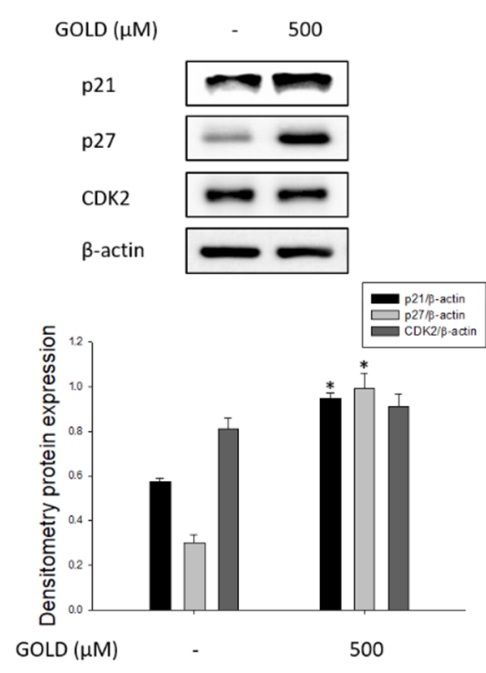

(F)

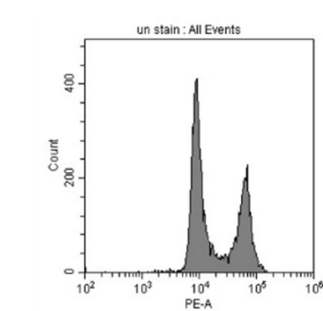

$\operatorname{GOLD}(\mu \mathrm{M})$

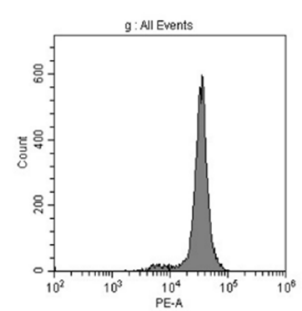

500

Figure 3. Effects of GOLD on inflammatory mediators, ROS production, and cell cycle. SV40 MES 13 cells were treated with GOLD $(500 \mu \mathrm{M})$ for $30 \mathrm{~min}$ or $24 \mathrm{~h}$. (A,B) Reactive oxygen species (ROS) production was determined as described in the Materials and Methods. Mesangial cells were treated with vehicle (medium) in the presence or absence of GOLD $(500 \mu \mathrm{M})$ for $30 \mathrm{~min}$. The amount of ROS in mesangial cells was analyzed using confocal microscopy. (C) Cells were incubated with anti-RAGE primary antibodies, followed by FITC-labeled anti-rabbit IgG. Cells were observed under fluorescence microscopy at $\times 400$ magnification. (D,E) The phosphorylation levels of MAPK and the production of proinflammatory cytokines were detected using Western blotting. (F) Mesangial cells were incubated for $30 \mathrm{~min}$ in the absence or presence of GOLD $(500 \mu \mathrm{M})$. The levels of cell cycle-related proteins were evaluated using Western blotting. (G) SV40 MES 13 cells were cultured in a medium containing GOLD $(500 \mu \mathrm{M})$ for $24 \mathrm{~h}$, fixed with $70 \%$ ethanol, stained with propidium iodide solution, and assessed using fluorescence-activated cell sorting. $\beta$-actin levels were used as the internal control. Scale bars, $20 \mu \mathrm{m}$. Data are expressed as the mean \pm SEM of three independent experiments. ${ }^{*} p<0.05$ indicates a significant difference compared to the untreated group.

Various factors are involved in the inflammatory response in kidney diseases. Therefore, we examined whether the activating effect of GOLD on the inflammatory response is MAPK pathway dependent. Our results showed that GOLD dramatically increased the phosphorylation of MAPK proteins, extracellular signal-regulated kinase 1/2 (ERK1/2), cJun N-terminal kinases (JNK), and p38 compared to that in the untreated group (Figure 3D). Furthermore, we investigated the expression of proinflammatory cytokines, such as tumor necrosis factor- $\alpha$ (TNF- $\alpha$ ), interleukin (IL)-6, IL-1 $\beta$, and IL-18. The production of proinflammatory cytokines was remarkably induced by incubation with GOLD (Figure 3E). These results indicate that the GOLD-induced inflammatory responses are related to the MAPK and inflammatory cytokine signaling pathways.

Next, to assess the cell cycle and identify cell cycle regulators that modulate mesangial cell differentiation, we first performed flow cytometry and Western blot analyses to determine changes in cell proliferation induced by GOLD. Flow cytometry analysis showed that GOLD significantly regulated the cell cycle (Figure 3F,G). Therefore, we further investigated the expression of cell cycle-related genes, such as p21, p27, and CDK2. The expression of p21 and p27 was upregulated by GOLD treatment, but levels of CDK2 were unchanged in SV40 MES 13 cells. Collectively, these results indicate that GOLD stimulates inflammatory responses and oxidative stress in SV40 MES 13 cells. In addition, these processes affect cell cycle regulation and cell differentiation by regulating cell cycle-related factors. 


\subsection{Effects of GOLD on NRF2 and the GLO1 Signaling Pathway}

Next, we investigated the effect of GOLD on the expression of NRF2 and GLO1 in mesangial cells. The NRF2/GLO1 signaling system is an important antioxidant activity signaling system [21,30]. As shown in Figure 4A,C, GOLD significantly inhibited the expression of NRF2 and GLO1 in mesangial cells. Treatment of cells with GOLD resulted in decreased NRF2 and GLO1 mRNA levels compared to those in untreated cells (Figure 4B,D). When NRF2 is activated, it moves into the nucleus. Immunofluorescence microscopy confirmed the expression of NRF2 and revealed that translocation of NRF2 from the cytosol to the nucleus was suppressed by GOLD in SV40 MES 13 cells (Figure 4E). These results indicate that GOLD decreases the expression levels of NRF2 and GLO1.

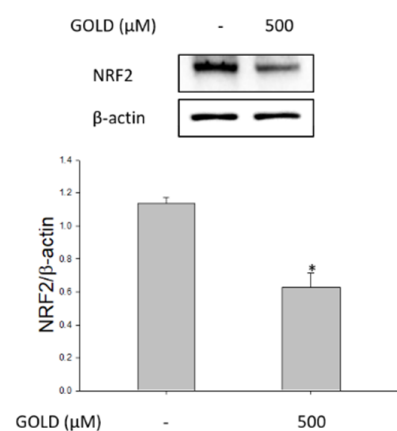

(A)

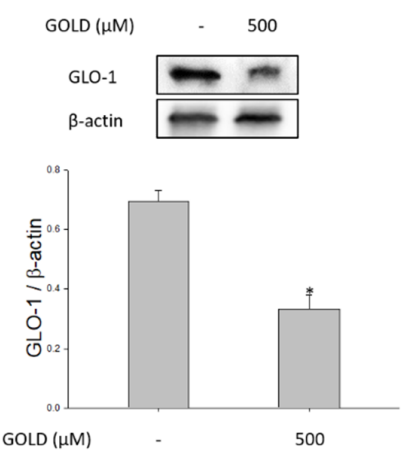

(C)

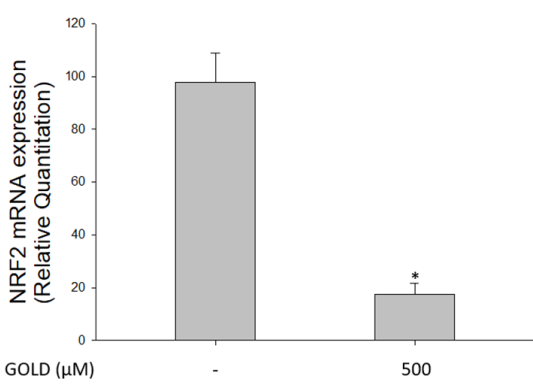

(B)

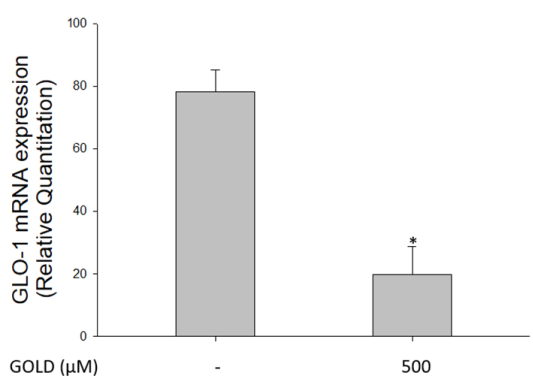

(D)

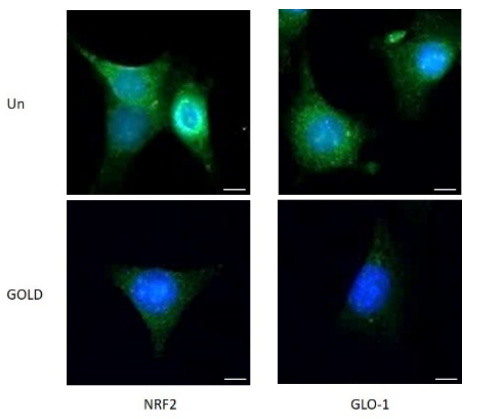

(E)

Figure 4. Effects of GOLD on nuclear factor erythroid 2-related factor 2 (NRF2) and the glyoxalase 1 (GLO1) signaling pathway. SV40 MES 13 cells were incubated in the presence or absence of GOLD $(500 \mu \mathrm{M})$ for $24 \mathrm{~h}$. (A,C) Protein levels of NRF2 and GLO1 were measured using Western blotting. (B,D) mRNA levels of NRF2 and GLO1 were determined using RT-qPCR. (E) Cells were incubated with anti-NRF2 and -GLO1 primary antibodies, followed by FITC-labeled anti-rabbit IgG. Cells were observed under fluorescence microscopy at $\times 400$ magnification. $\beta$-actin levels were used as the internal control. Scale bars, $20 \mu \mathrm{m}$. Data are expressed as the mean $\pm \mathrm{SEM}$ of three independent experiments. ${ }^{*} p<0.05$ indicates a significant difference compared to the untreated group. 


\subsection{Regulation of Mitochondrial Function by GOLD}

To evaluate mitochondrial function triggered in GOLD-stimulated cells, we investigated the morphological and functional changes in mitochondria in SV40 MES 13 cells. First, we measured the accumulation and mass of mitochondria using MitoTracker under confocal microscopy. GOLD-stimulated cells showed decreased mitochondria expression and morphology compared to the control group (Figure 5A). As shown in Figure 5B,C, we further examined the JC-1 staining of GOLD-stimulated mitochondria to confirm mitochondrial membrane potential. These results show that MMP is depolarized by GOLD treatment in mesangial cells. Measurement of the MMP, as an indicator of mitochondrial activity, revealed a marked reduction in that of the GOLD-treated group, which was consistent with the changes in mitochondrial accumulation and morphology. Additionally, we identified cellular adenosine triphosphate (ATP) production as an essential function of the mitochondria, showing that GOLD suppressed ATP production in mesangial cells (Figure 5D). Moreover, we examined the effect of GOLD on glucose uptake during mitochondrial dysfunction. Treatment with GOLD significantly reduced the uptake of glucose in mesangial cells compared to that in the control group (Figure 5E).

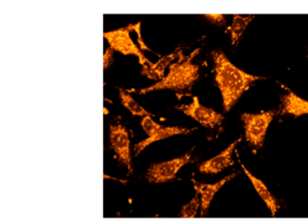

$\operatorname{GOLD}(\mu \mathrm{M})$

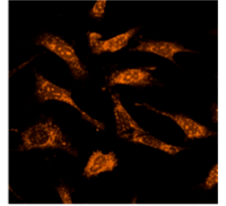

500

(A)

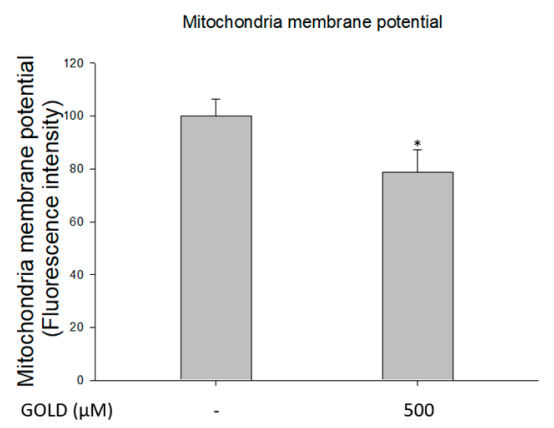

(C)

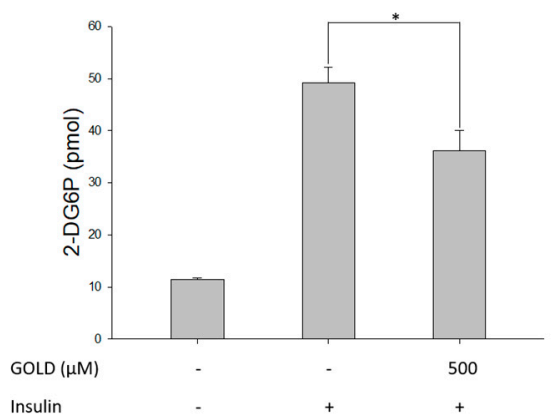

(E)

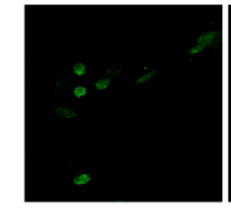

GOLD $(\mu M)$

FCCP
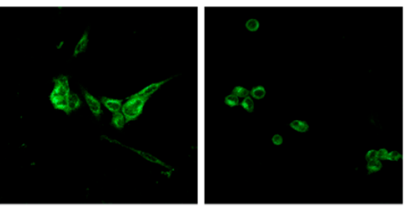

500

(B)
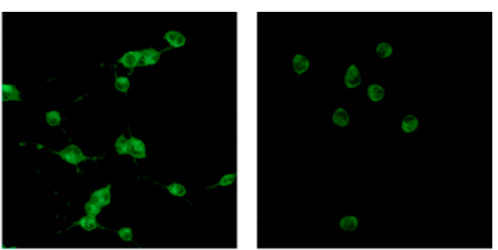

$\operatorname{GOLD}(\mu \mathrm{M})$

500
(D)

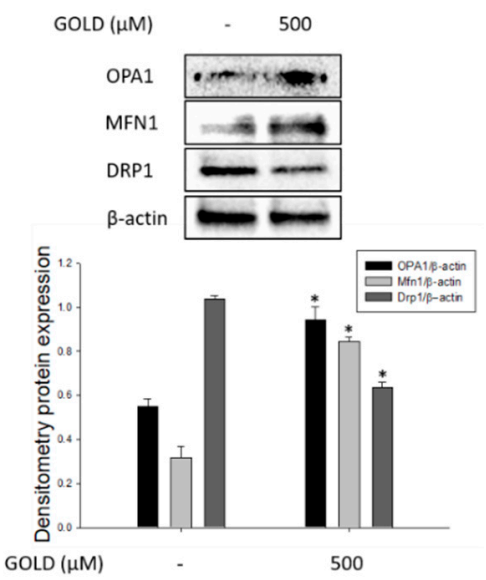

(F)

Figure 5. Cont. 


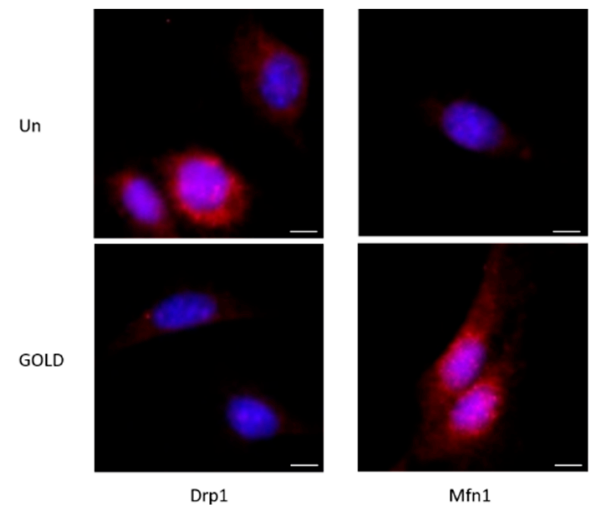

(G)

Figure 5. Regulation of mitochondrial function by GOLD. The expression and function of mitochondria under GOLD treatment $(500 \mu \mathrm{M})$ were investigated. (A) SV40 MES 13 cells were incubated with MitoTracker Orange. Mitochondrial morphology and expression were investigated using confocal microscopy. (B) Mitochondrial membrane potential was measured using an ELISA kit. Mitochondrial genes were assessed in SV40 MES 13 cells. FCCP expression was measured as a positive control. (C) The mitochondrial membrane potential was determined using confocal microscopy and an ELISA kit. Quantitative analysis of tetraethylbenzimidazolylcarbocyanine iodide (JC-1)-stained cells using flow cytometry. SV40 MES 13 cells were pretreated with $500 \mu \mathrm{M}$ GOLD for $24 \mathrm{~h}$ and then stained with JC-1 for $20 \mathrm{~min}$. (D) Adenosine triphosphate (ATP) content in the untreated and GOLD-treated groups. Data are expressed as the mean \pm standard deviation (represented by vertical bars; $n=3$ ). (E) Basal glucose transport and insulin-stimulated glucose transport rates are shown. The basal rate refers to the rate of glucose transport in the absence of insulin. All values were normalized to the basal rate. (F) The expression of mitochondrial fusion and fission-related genes was investigated to determine mitochondrial dynamics using Western blotting. $\beta$-actin expression was measured as an internal control. (G) Cells were incubated with anti-DRP1 and-MFN1 primary antibodies, followed by Alexa 488-labeled anti-mouse IgG. Cells were observed under fluorescence microscopy at $\times 400$ magnification. Data are expressed as the mean \pm SEM of three independent experiments. ${ }^{*} p<0.05$ indicates a significant difference compared to the untreated group.

Next, we determined the expression of mitochondrial fusion and fission-related genes to investigate mitochondrial dynamics. As shown in Figure 5F,G, the expression of the mitochondrial fission-related genes dynamin-related protein 1 (DRP1) and mitochondrial fission factor (MFF) was dramatically increased after incubation with GOLD, whereas that of mitofusin-1 (MFN1) and optic atrophy 1 (OPA1) was decreased in mesangial cells. Furthermore, we confirmed the changes in mitochondrial fission and fusion-related gene expression in GOLD-stimulated cells using confocal microscopy. These results suggest that GOLD reduces mitochondrial function by causing genetic and morphological changes in the mitochondria.

\subsection{Changes in Signaling through RAGE Suppression}

Next, we examined whether RAGE signaling pathways contribute to inflammatory mediators and mitochondrial function in GOLD-activated mesangial cells and investigated changes in the inflammatory response by transfecting cells with RAGE siRNA. Prior to these experiments, we confirmed the knockdown efficiency of RAGE siRNA. siRNA reduced the expression of RAGE by approximately 46\% (Figure 6A). As shown in Figure 6B, when RAGE was suppressed by siRNA, ROS production significantly decreased compared to that in the control siRNA transfection group. The NRF2/GLO1 signaling pathway was found to be closely related to the oxidative stress response caused by AGEs in numerous disorders. As expected, RAGE suppression increased the activity of the NRF2/GLO1 signaling pathway (Figure 6C). In kidney disease, inflammatory cytokine overproduction 
through the AGE-RAGE axis promotes lesion exacerbation. As shown in Figure 6D, it was confirmed that cytokine production induced by GOLD was inhibited through RAGE suppression. Stimulation with AGEs crucially induces RAGE activation, stimulating inflammatory signaling. We confirmed mitochondrial dynamics that mitochondrial function was also restored through the suppression of RAGE (Figure 6E). Taken together, these results suggest that the inflammatory response stimulates the overproduction of RAGE and inflammatory mediators, causing impaired kidney function. Furthermore, it was shown that by inhibiting mitochondrial function, these processes aggravate the mesangial function condition of mesangial cells.

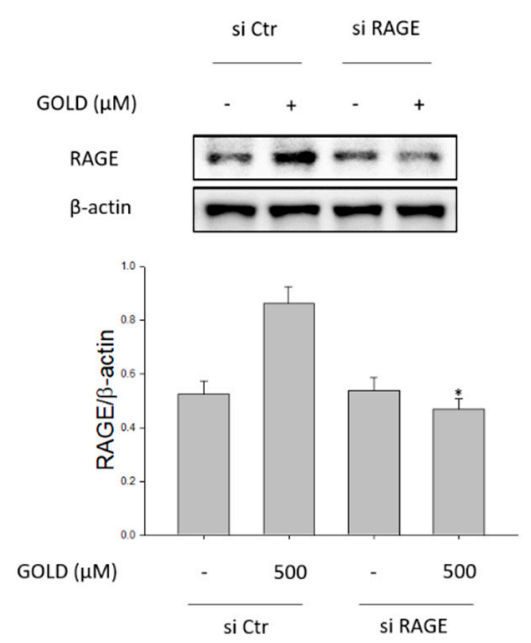

(A)

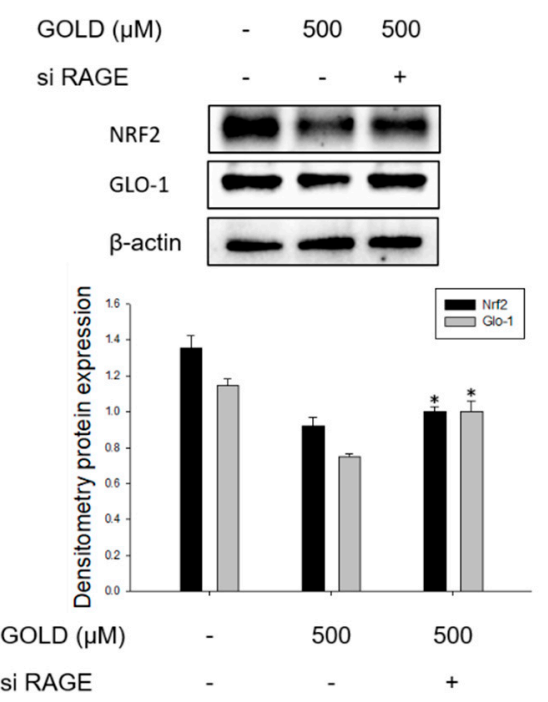

(C)

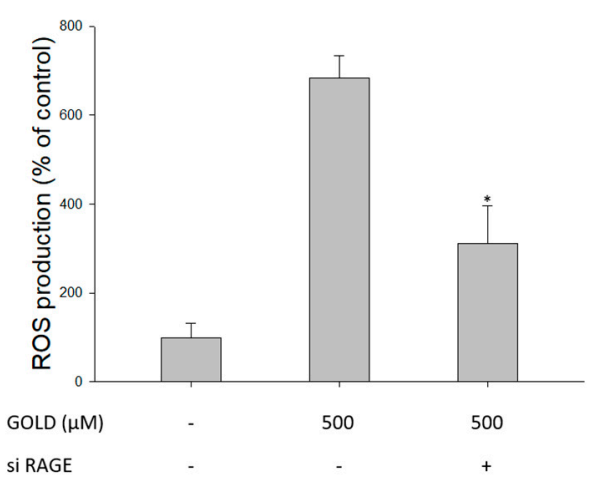

(B)

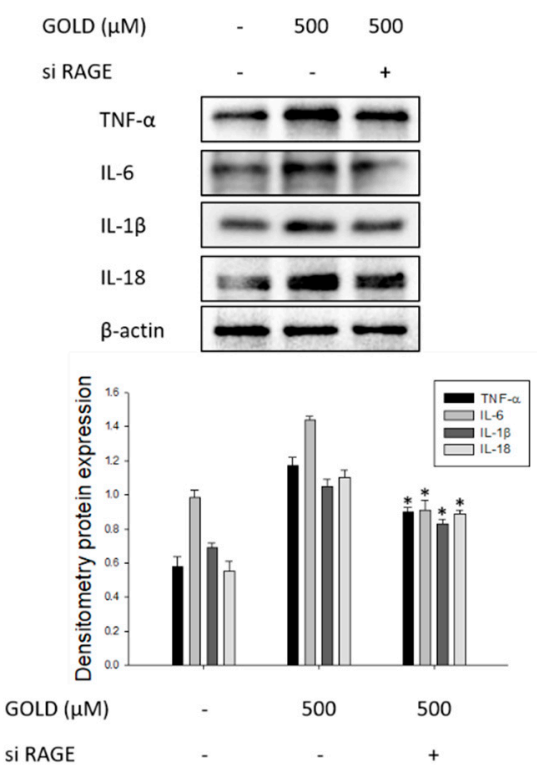

(D)

Figure 6. Cont. 


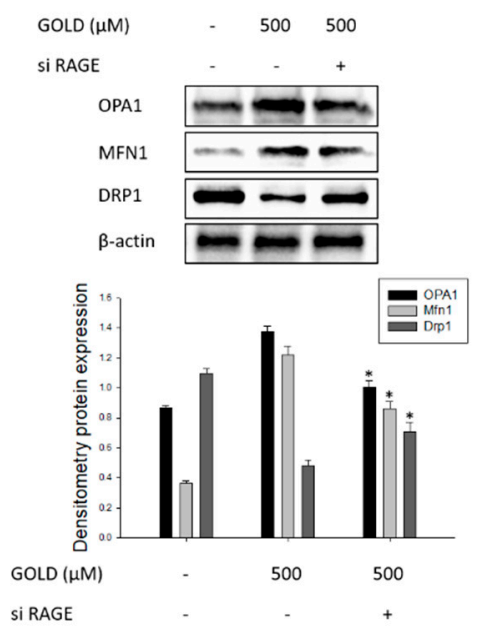

(E)

Figure 6. Changes in signaling through RAGE suppression. Effects of RAGE on GOLD-stimulated SV40 MES 13 cells. (A) SV40 MES 13 cells were transfected with control small interfering RNA (siRNA) or RAGE siRNA and then treated with GOLD. (B) SV40 MES 13 cells were transfected with RAGE siRNA and then stimulated with GOLD $(500 \mu \mathrm{M})$ for $30 \mathrm{~min}$. ROS levels were determined using confocal microscopy. (C,D) Protein levels of NRF2, GLO1, and proinflammatory cytokines were determined using Western blotting, with $\beta$-actin as an internal control. (E) Mitobiogenesis was measured by detecting mitochondrial genes in SV40 MES 13 cells. Data are expressed as the mean \pm SEM of three independent experiments. ${ }^{*} p<0.05$ indicates a significant difference compared to the GOLD-treated group.

\section{Discussion}

This study identified a specific mechanism through the effect that GOLD, a GOinduced AGE produced by glycation, produces excessive ROS production and induces an inflammatory response in mesangial cells. It also affects oxidative stress by changing the NRF/GLO1 signaling pathway in mesangial damage. We reported that GOLD increases RAGE expression on the surface of mesangial cells and causes mesangial damage by bonding to the surface of RAGE in silico. In many studies, the toxic effects of AGEs have been investigated, and related research is being conducted on various diseases. However, most studies have focused on the toxicity and disease induction caused by AGEs. In addition, most research is limited to AGEs such as pentosidine, $\mathrm{N}^{\epsilon}$ (Carboxymethyl)lysine (CML), and MG-H1 [31-33]. Specific AGEs, such as the well-known CML and Ne-(Carboxyethyl)lysine (CEL), are harmful to the kidneys [34]. In this study, we have shown directly how GOLD itself has a detrimental effect in mesangial cells. We sought to determine the effect of GOLD on several important renal cells such as mesangial cells, epithelial cells, and podocytes based on AGE-related studies $[35,36]$. When we checked the effect of AGEs using various types of kidney cells, it was confirmed that the critical effect was shown on mesangial cells. Besides, we conducted a more comprehensive study that confirmed the inflammatory effect of GOLD and the oxidative stress mechanism by which the GOLD effect occurs in mesangial cells. Therefore, the study of GOLD could be crucial due to its effect on the damage of mesangial cells. Furthermore, the association of GOLD with mesangial cells could be important to unveil its association with other diseases. In addition, many previous studies have investigated the involvement of AGEs as well as GOLD in a variety of diseases and found they are associated with chronic kidney disease. Several studies have also investigated the toxicity of GO-derived AGEs [37,38]. These studies show that mesangial cell damage is increased through the regulation of RAGE expression and specific signaling by the AGE-RAGE axis. We demonstrated the interaction between downstream mechanisms through the signaling of GO-derived AGEs through the interaction of GOLD and RAGE in mesangial cells. 
AGEs can be produced in various forms from several types of precursors that cause the Maillard reaction. The main factor that can trigger this reaction in our body is food intake [39]. Endogenous generation in living organisms, including humans, is also a critical factor in the formation of AGEs. The latter is the product of Maillard reactions initiated by a nonenzymatic reaction between a carbonyl compound and an amine group [40]. The reaction forms a number of Maillard reaction product intermediates with different molecular sizes and compositions depending on the reaction compound, and compounds with various compositions and molecular weights are involved in the formation of AGEs as they contain various peptides [41,42]. In particular, GOLD is a GO-derived AGE often produced by fructose. These dicarbonyl-derived AGEs represent major chemical modifications that accumulate in tissue proteins with age and in chronic diseases, such as diabetes and chronic kidney disease [34,43]. Therefore, glyoxal-derived AGEs have been investigated in various ways, some of which have been found to be directly involved in AGE formation and RAGE interaction [44,45]. GOLD is an AGE that shows strong toxicity in the body and is used as an important indicator of protein glycation [46]. In addition, the cross-linking of proteins, including Lys, glycosylated Lys, and Arg, rouses great interest because it significantly impairs physiological functions and induces various AGE-related diseases [47]. In particular, GOLD, which is produced from two Lys residues and glyoxal, was found in tissue as an important indicator of diseases related to glycation products. Despite the great advances made by these biochemical studies, data on how closely the glycation reaction of human proteins can be reproduced by model systems using amino acid-sugar mixtures remain limited.

The body produces and accumulates AGEs through various reactions from food. In this regard, many studies have focused on the effect of AGEs and found that AGEs are associated with various diseases in humans. AGEs are associated with the incidence of kidney disease and lesion exacerbation [4,8]. Although these studies have shown detrimental effects of AGEs, few have investigated the precise mechanisms triggering kidney damage. Most of the research is limited to studies on specific AGEs, such as CML and CEL. Herein, we have confirmed that GOLD induces damage to the mesangial and demonstrated the mechanism of mesangial damage in mesangial cells. Therefore, our study focuses on new goals in the treatment of kidney disease by discovering novel mechanisms by which AGE contributes to kidney damage.

RAGE, present on the surface of the plasma membrane, is a member of the Ig superfamily. It binds to AGEs on the cell surface and transmits an intracellular signal $[18,48]$. Therefore, it is important to determine how GOLD reacts with RAGE to transmit a signal into the cell. The docking for Glide is to bind a flexible ligand to a rigid protein. MM-GBSA is a broadly used method for binding free energy estimation of a small molecule and receptor $[49,50]$. Molecular dynamics simulation, which is used to identify the precise binding model, is the basis of the MM-GBSA calculation, and the binding free energy is an important parameter of this calculation. To define an accurate binding model between GOLD and RAGE, MM-GBSA calculation was performed. We predicted the binding and structural association between GOLD and RAGE through the binding study of AGE and RAGE. The chemical and structural association of AGE and RAGE elicits a variety of intracellular responses and is associated with renal disorders. The interaction between AGEs and RAGE results in various outcomes, such as increased free radicals, increased oxidative stress, and decreased mitochondrial function, causing damage to the kidneys [51]. Therefore, the AGE-RAGE axis is an important factor when studying the effects of harmful AGEs on the kidneys. Our study showed that GOLD induced RAGE expression in kidney cells. This also confirms the importance of the structural bond between GOLD and RAGE in kidney damage. Therefore, we demonstrate that not only GOLD-induced RAGE production, but also the combination of AGEs and RAGE, are important and trigger a detrimental effect on the kidneys. These results show that regulation of the AGE-RAGE axis significantly affects mesangial cells. As a molecular mechanism involving glycation, AGEs bind to RAGE and accelerate processes such as fibrosis, apoptosis, and inflammation via subsequent 
activation of the AGE-RAGE axis [52]. Glyoxalase detoxifies AGE precursors such as glyoxal and methylglyoxal, thereby inhibiting the generation of AGEs and the activation of the AGE-RAGE axis [53]. The glyoxalase system catalyzes the precursors of AGEs using two thiol-dependent enzymes, GLO1/2 [54]. Therefore, the glyoxalase system essentially affects glycation stress signal removal induced by the AGE-RAGE axis.

AGEs induce ROS production by activating the signaling pathway via RAGE. Recent studies have suggested that the AGE-RAGE axis plays an essential role in ROS generation and gene activation $[55,56]$. Accumulated AGE also mediates several effects through RAGE, activating pathways that promote excessive production of ROS. Our research focuses on ROS production through the interaction of GOLD with RAGE. This process accelerates oxidative stress by reducing the activity of glyoxalase, which breaks down the precursors that produce AGEs. Eventually, the AGE-RAGE axis induces overproduction of intracellular ROS $[56,57]$. Furthermore, it worsens diseases and lesions through the activity of nicotinamide adenine dinucleotide phosphate (NADPH) oxidase and oxidative stress. During oxidative stress, AGEs induce excessive amounts of substances that damage cells, such as cytokines and ROS [58]. AGE is well known to be associated with ROS production and mitochondrial dysfunction in kidney-related diseases. In addition, the AGE-RAGE axis causes functional and morphological changes in mitochondria and an overproduction of ROS associated with kidney disease [56]. Therefore, we investigated the effect on mitochondrial dysfunction by a specific AGE, GOLD. Mitochondria are involved in many aspects, including the physiological and pathological roles of ROS production [57,59]. Thus, mitochondrial and ROS interactions suggest disease-related mechanisms. In this study, we examined the detrimental effects of ROS and the mechanisms involved in kidney damage and associated mitochondrial dysfunction. We identified a more accurate mechanism by identifying the link between RAGE-mediated ROS production and oxidative stress. It was confirmed that GOLD promotes RAGE expression and is involved in ROS production through oxidative stress. In this process, mitochondrial dysfunction was found to be caused by ROS production. Therefore, we emphasize that GOLD-induced mitochondrial dysfunction and excessive ROS production induce lesion exacerbation. It was also demonstrated that blocking ROS production and RAGE expression decreases the inflammatory response in mesangial cells.

Oxidative stress and inflammatory reactions are closely related to the development and progression of kidney disease. Oxidative stress that exacerbates kidney-related diseases is due to increased production of ROS and decreased antioxidant capacity $[4,60]$. The NRF2 transcription factor is well known, and oxidative stress is a key gene regulator. NRF2 activation regulates oxidative stress and inflammatory responses $[19,22]$. Based on the current observations, the production of ROS and changes in mitochondrial function due to the effect of GOLD suggest a change in NRF2 activity. NRF2 has been suggested to regulate inflammatory response-related factors, such as cytokines, and oxidative stress regulators depending on its transcription in mesangial cells [61].

\section{Conclusions}

This study demonstrated damage to the renal cells through GOLD-RAGE interaction in mesangial cells. GOLD induces excessive inflammatory reactions by binding to RAGE in mesangial cells. The detrimental action of GOLD on the inflammatory response is mediated by the NRF2/GLO1 signaling pathway in renal cells. In addition, ROS production caused by AGE-RAGE binding essentially worsens mesangial damage and is a critical factor in the disruption of mitochondrial function. In conclusion, we have confirmed that GOLD is naturally generated from the body environment. Furthermore, GOLD has been found to crucially influence renal cell damages. Therefore, this study shows the importance of reducing GOLD-induced damage in the body and that the damage caused by GOLD can be controlled. 
Author Contributions: H.-W.L., M.J.G. and S.K.H. conceived and designed the experiments. H.-W.L., M.J.G., J.-Y.L. and S.L. performed the experiments. H.-W.L., M.J.G., Y.K., I.-W.C. and S.K.H. analyzed data and H.-W.L., M.J.G. and S.K.H. wrote the manuscript. Y.K., I.-W.C. and S.K.H. contributed reagents/materials/analysis tools. All authors have read and agreed to the published version of the manuscript.

Funding: This research was supported by the Main Research Program (E 0210203) of the Korea Food Research Institute (KFRI) funded by the Ministry of Science and National Research Foundation of Korea (NRF) grant funded by the Korea government (MSIT) (NRF-2020R1A2C2012608).

Institutional Review Board Statement: Not applicable.

Informed Consent Statement: Not applicable.

Data Availability Statement: The data presented in this study are available in article.

Conflicts of Interest: The authors have no conflict of interest to disclose.

\section{References}

1. Ledl, F.; Schleicher, E. New aspects of the Maillard reaction in foods and in the human body. Angew. Chem. Int. Ed. Engl. 1990, 29, 565-594. [CrossRef]

2. Waller, G.R.; Feather, M.S. The Maillard reaction in foods and nutrition. In Proceedings of the ACS symposium series (USA), Las Vegas, NV, USA, 29 April 1983.

3. Van Nguyen, C. Toxicity of the AGEs generated from the Maillard reaction: On the relationship of food-AGEs and biological-AGEs. Mol. Nutr. Food Res. 2006, 50, 1140-1149. [CrossRef] [PubMed]

4. Heidland, A.; Sebekova, K.; Schinzel, R. Advanced glycation end products and the progressive course of renal disease. Am. J. Kidney Dis. 2001, 38, S100-S106. [CrossRef] [PubMed]

5. Antognelli, C.; Cecchetti, R.; Riuzzi, F.; Peirce, M.J.; Talesa, V.N. Glyoxalase 1 sustains the metastatic phenotype of prostate cancer cells via EMT control. J. Cell. Mol. Med. 2018, 22, 2865-2883. [CrossRef] [PubMed]

6. Chen, J.-H.; Lin, X.; Bu, C.; Zhang, X. Role of advanced glycation end products in mobility and considerations in possible dietary and nutritional intervention strategies. Nutr. Metab. (Lond.) 2018, 15, 72. [CrossRef]

7. Bohlender, J.M.; Franke, S.; Stein, G.; Wolf, G. Advanced glycation end products and the kidney. Am. J. Physiol.-Ren. Physiol. 2005, 289, F645-F659. [CrossRef]

8. Thornalley, P.J. Advanced glycation end products in renal failure. J. Ren. Nutr. 2006, 16, 178-184. [CrossRef]

9. Zhou, Q.; Cheng, K.-W.; Gong, J.; Li, E.T.S.; Wang, M. Apigenin and its methylglyoxal-adduct inhibit advanced glycation end products-induced oxidative stress and inflammation in endothelial cells. Biochem. Pharmacol. 2019, 166, 231-241. [CrossRef]

10. Chuah, Y.K.; Basir, R.; Talib, H.; Tie, T.H.; Nordin, N. Receptor for advanced glycation end products and its involvement in inflammatory diseases. Int. J. Inflamm. 2013, 2013, 403460. [CrossRef]

11. Lal, M.A.; Brismar, H.; Eklöf, A.-C.; Aperia, A. Role of oxidative stress in advanced glycation end product-induced mesangial cell activation. Kidney Int. 2002, 61, 2006-2014. [CrossRef]

12. Mallipattu, S.K.; Uribarri, J. Advanced glycation end product accumulation: A new enemy to target in chronic kidney disease? Curr. Opin. Nephrol. Hypertens. 2014, 23, 547. [CrossRef]

13. Koch, M.; Chitayat, S.; Dattilo, B.M.; Schiefner, A.; Diez, J.; Chazin, W.J.; Fritz, G. Structural basis for ligand recognition and activation of RAGE. Structure 2010, 18, 1342-1352. [CrossRef] [PubMed]

14. Matsui, T.; Yamagishi, S.-I.; Takeuchi, M.; Ueda, S.; Fukami, K.; Okuda, S. Irbesartan inhibits advanced glycation end product (AGE)-induced proximal tubular cell injury in vitro by suppressing receptor for AGEs (RAGE) expression. Pharmacol. Res. 2010, 61,34-39. [CrossRef]

15. Yamagishi, S.-I.; Matsui, T. Advanced glycation end products, oxidative stress and diabetic nephropathy. Oxidative Med. Cell. Longev. 2010, 3, 101-108. [CrossRef]

16. Bierhaus, A.; Humpert, P.M.; Stern, D.M.; Arnold, B.; Nawroth, P.P. Advanced glycation end product receptor-mediated cellular dysfunction. Ann. N. Y. Acad. Sci. 2005, 1043, 676-680. [CrossRef]

17. Taneja, S.; Vetter, S.W.; Leclerc, E. Hypoxia and the Receptor for Advanced Glycation End Products (RAGE) Signaling in Cancer. Int. J. Mol. Sci. 2021, 22, 8153. [CrossRef] [PubMed]

18. Schmidt, A.M.; Hori, O.; Cao, R.; Du Yan, S.; Brett, J.; Wautier, J.-L.; Ogawa, S.; Kuwabara, K.; Matsumoto, M.; Stern, D. RAGE: A novel cellular receptor for advanced glycation end products. Diabetes 1996, 45, S77-S80. [CrossRef] [PubMed]

19. Negi, G.; Kumar, A.; Joshi, R.P.; Sharma, S.S. Oxidative stress and Nrf2 in the pathophysiology of diabetic neuropathy: Old perspective with a new angle. Biochem. Biophys. Res. Commun. 2011, 408, 1-5. [CrossRef]

20. Linden, E.; Cai, W.; He, J.C.; Xue, C.; Li, Z.; Winston, J.; Vlassara, H.; Uribarri, J. Endothelial dysfunction in patients with chronic kidney disease results from advanced glycation end products (AGE)-mediated inhibition of endothelial nitric oxide synthase through RAGE activation. Clin. J. Am. Soc. Nephrol. 2008, 3, 691-698. [CrossRef] 
21. Delle Monache, S.; Pulcini, F.; Frosini, R.; Mattei, V.; Talesa, V.N.; Antognelli, C. Methylglyoxal-Dependent Glycative Stress Is Prevented by the Natural Antioxidant Oleuropein in Human Dental Pulp Stem Cells through Nrf2/Glo1 Pathway. Antioxidants (Basel) 2021, 10, 716. [CrossRef]

22. Kim, H.J.; Vaziri, N.D. Contribution of impaired Nrf2-Keap1 pathway to oxidative stress and inflammation in chronic renal failure. Am. J. Physiol.-Ren. Physiol. 2010, 298, F662-F671. [CrossRef]

23. Ansari, M.A. Sinapic acid modulates Nrf2/HO-1 signaling pathway in cisplatin-induced nephrotoxicity in rats. Biomed. Pharmacother. 2017, 93, 646-653. [CrossRef] [PubMed]

24. Sahin, K.; Orhan, C.; Tuzcu, Z.; Tuzcu, M.; Sahin, N. Curcumin ameloriates heat stress via inhibition of oxidative stress and modulation of Nrf2/HO-1 pathway in quail. Food Chem. Toxicol. 2012, 50, 4035-4041. [CrossRef]

25. Lee, H.W.; Gu, M.J.; Lee, J.Y.; Lee, S.; Kim, Y.; Ha, S.K. Methylglyoxal-Lysine Dimer, an Advanced Glycation End Product, Induces Inflammation via Interaction with RAGE in Mesangial Cells. Mol. Nutr. Food Res. 2021, 13, e2000799. [CrossRef] [PubMed]

26. Lionta, E.; Spyrou, G.; Vassilatis, D.K.; Cournia, Z. Structure-based virtual screening for drug discovery: Principles, applications and recent advances. Curr. Top. Med. Chem. 2014, 14, 1923-1938. [CrossRef]

27. Teissier, T.; Boulanger, É. The receptor for advanced glycation end-products (RAGE) is an important pattern recognition receptor (PRR) for inflammaging. Biogerontology 2019, 20, 279-301. [CrossRef]

28. Xue, J.; Ray, R.; Singer, D.; Böhme, D.; Burz, D.S.; Rai, V.; Hoffmann, R.; Shekhtman, A. The receptor for advanced glycation end products (RAGE) specifically recognizes methylglyoxal-derived AGEs. Biochemistry 2014, 53, 3327-3335. [CrossRef]

29. Chen, D.; Oezguen, N.; Urvil, P.; Ferguson, C.; Dann, S.M.; Savidge, T.C. Regulation of protein-ligand binding affinity by hydrogen bond pairing. Sci. Adv. 2016, 2, e1501240. [CrossRef]

30. Antognelli, C.; Trapani, E.; Delle Monache, S.; Perrelli, A.; Daga, M.; Pizzimenti, S.; Barrera, G.; Cassoni, P.; Angelucci, A.; Trabalzini, L.; et al. KRIT1 loss-of-function induces a chronic Nrf2-mediated adaptive homeostasis that sensitizes cells to oxidative stress: Implication for Cerebral Cavernous Malformation disease. Free. Radic. Biol. Med. 2018, 115, 202-218. [CrossRef] [PubMed]

31. Miyata, T.; Ueda, Y.; Horie, K.; Nangaku, M.; Tanaka, S.; van Ypersele de Strihou, C.; Kurokawa, K. Renal catabolism of advanced glycation end products: The fate of pentosidine. Kidney Int. 1998, 53, 416-422. [CrossRef] [PubMed]

32. Piroddi, M.; Palazzetti, I.; Quintaliani, G.; Pilolli, F.; Montaldi, M.; Valentina, V.; Libetta, C.; Galli, F. Circulating levels and dietary intake of the advanced glycation end-product marker carboxymethyl lysine in chronic kidney disease patients on conservative predialysis therapy: A pilot study. J. Ren. Nutr. 2011, 21, 329-339. [CrossRef] [PubMed]

33. Boehm, B.; Schilling, S.; Rosinger, S.; Lang, G.E.; Lang, G.; Kientsch-Engel, R.; Stahl, P. Elevated serum levels of N $\varepsilon$-carboxymethyllysine, an advanced glycation end product, are associated with proliferative diabetic retinopathy and macular oedema. Diabetologia 2004, 47, 1376-1379. [CrossRef]

34. Rabbani, N.; Thornalley, P.J. Advanced glycation end products in the pathogenesis of chronic kidney disease. Kidney Int. 2018, 93, 803-813. [CrossRef] [PubMed]

35. Bondeva, T.; Rüster, C.; Franke, S.; Hammerschmid, E.; Klagsbrun, M.; Cohen, C.D.; Wolf, G. Advanced glycation end-products suppress neuropilin-1 expression in podocytes. Kidney Int. 2009, 75, 605-616. [CrossRef] [PubMed]

36. Oldfield, M.D.; Bach, L.A.; Forbes, J.M.; Nikolic-Paterson, D.; McRobert, A.; Thallas, V.; Atkins, R.C.; Osicka, T.; Jerums, G.; Cooper, M.E. Advanced glycation end products cause epithelial-myofibroblast transdifferentiation via the receptor for advanced glycation end products (RAGE). J. Clin. Investig. 2001, 108, 1853-1863. [CrossRef]

37. Karachalias, N.; Babaei-Jadidi, R.; Ahmed, N.; Thornalley, P. Accumulation of fructosyl-lysine and advanced glycation end products in the kidney, retina and peripheral nerve of streptozotocin-induced diabetic rats. Biochem. Soc. Trans. 2003, 31, 1423-1425. [CrossRef] [PubMed]

38. Holik, A.K.; Lieder, B.; Kretschy, N.; Somoza, M.M.; Ley, J.P.; Hans, J.; Somoza, V. The advanced glycation end product Necarboxymethyllysine and its precursor glyoxal increase serotonin release from Caco-2 cells. J. Cell. Biochem. 2018, 119, $2731-2741$. [CrossRef] [PubMed]

39. Wu, C.-H.; Huang, S.-M.; Lin, J.-A.; Yen, G.-C. Inhibition of advanced glycation endproduct formation by foodstuffs. Food Funct. 2011, 2, 224-234. [CrossRef]

40. Yamagishi, S.-I.; Ueda, S.; Okuda, S. Food-derived advanced glycation end products (AGEs): A novel therapeutic target for various disorders. Curr. Pharm. Des. 2007, 13, 2832-2836. [CrossRef]

41. Henle, T. Maillard reaction of proteins and advanced glycation end products (AGEs) in food. In Process-Induced Food Toxicants; John Wiley and Sons, Inc.: Hoboken, NJ, USA, 2009; pp. 215-242.

42. Singh, R.; Barden, A.; Mori, T.; Beilin, L. Advanced glycation end-products: A review. Diabetologia 2001, 44, 129-146. [CrossRef] [PubMed]

43. Rabbani, N.; Thornalley, P.J. The critical role of methylglyoxal and glyoxalase 1 in diabetic nephropathy. Diabetes 2014, 63, 50-52. [CrossRef] [PubMed]

44. Yamada, H.; Sasaki, T.; Niwa, S.; Oishi, T.; Murata, M.; Kawakami, T.; Aimoto, S. Intact glycation end products containing carboxymethyl-lysine and glyoxal lysine dimer obtained from synthetic collagen model peptide. Bioorg. Med. Chem. Lett. 2004, 14, 5677-5680. [CrossRef] [PubMed]

45. Skovsted, I.; Christensen, M.; Breinholt, J.; Mortensen, S. Characterisation of a novel AGE-compound derived from lysine and 3-deoxyglucosone. Cell. Mol. Biol. (Noisy-le-Grand, Fr.) 1998, 44, 1159-1163. 
46. Wells-Knecht, K.J.; Brinkmann, E.; Wells-Knecht, M.C.; Litchfield, J.E.; Ahmed, M.U.; Reddy, S.; Zyzak, D.V.; Thorpe, S.R.; Baynes, J.W. New biomarkers of Maillard reaction damage to proteins. Nephrol. Dial. Transplant. 1996, 11, 41-47. [CrossRef]

47. Lederer, M.O.; Klaiber, R.G. Cross-linking of proteins by maillard processes: Characterization and detection of lysine-arginine cross-links derived from glyoxal and methylglyoxal. Bioorg. Med. Chem. 1999, 7, 2499-2507. [CrossRef]

48. Tan, A.L.; Forbes, J.M.; Cooper, M.E. AGE, RAGE, and ROS in diabetic nephropathy. In Seminars in nephrology; Saunders: Philadelphia, PA, USA, 2007; pp. 130-143.

49. Zhang, X.; Perez-Sanchez, H.; Lightstone, F.C. A comprehensive docking and MM/GBSA rescoring study of ligand recognition upon binding antithrombin. Curr. Top. Med. Chem. 2017, 17, 1631-1639. [CrossRef]

50. Genheden, S.; Ryde, U. The MM/PBSA and MM/GBSA methods to estimate ligand-binding affinities. Expert Opin. Drug Discov. 2015, 10, 449-461. [CrossRef]

51. Khazaei, M.; Karimi, J.; Sheikh, N.; Goodarzi, M.T.; Saidijam, M.; Khodadadi, I.; Moridi, H. Effects of Resveratrol on Receptor for Advanced Glycation End Products (RAGE) Expression and Oxidative Stress in the Liver of Rats with Type 2 Diabetes. Phytother. Res. 2016, 30, 66-71. [CrossRef]

52. Inagi, R. RAGE and glyoxalase in kidney disease. Glycoconj. J. 2016, 33, 619-626. [CrossRef]

53. Bartling, B.; Zunkel, K.; Al-Robaiy, S.; Dehghani, F.; Simm, A. Gene doubling increases glyoxalase 1 expression in RAGE knockout mice. Biochim. Biophys. Acta (BBA)-Gen. Subj. 2020, 1864, 129438. [CrossRef]

54. Rabbani, N.; Thornalley, P.J. Methylglyoxal, glyoxalase 1 and the dicarbonyl proteome. Amino Acids 2012, 42, 1133-1142. [CrossRef]

55. Rosca, M.G.; Mustata, T.G.; Kinter, M.T.; Ozdemir, A.M.; Kern, T.S.; Szweda, L.I.; Brownlee, M.; Monnier, V.M.; Weiss, M.F. Glycation of mitochondrial proteins from diabetic rat kidney is associated with excess superoxide formation. Am. J. Physiol.-Ren. Physiol. 2005, 289, F420-F430. [CrossRef] [PubMed]

56. Coughlan, M.T.; Thorburn, D.R.; Penfold, S.A.; Laskowski, A.; Harcourt, B.E.; Sourris, K.C.; Tan, A.L.; Fukami, K.; Thallas-Bonke, V.; Nawroth, P.P.; et al. RAGE-induced cytosolic ROS promote mitochondrial superoxide generation in diabetes. J. Am. Soc. Nephrol. 2009, 20, 742-752. [CrossRef] [PubMed]

57. Li, L.; Zhang, B.; Tao, Y.; Wang, Y.; Wei, H.; Zhao, J.; Huang, R.; Pei, Z. DL-3-n-butylphthalide protects endothelial cells against oxidative/nitrosative stress, mitochondrial damage and subsequent cell death after oxygen glucose deprivation in vitro. Brain Res. 2009, 1290, 91-101. [CrossRef]

58. Thallas-Bonke, V.; Thorpe, S.R.; Coughlan, M.T.; Fukami, K.; Yap, F.Y.; Sourris, K.C.; Penfold, S.A.; Bach, L.A.; Cooper, M.E.; Forbes, J.M. Inhibition of NADPH oxidase prevents advanced glycation end product-mediated damage in diabetic nephropathy through a protein kinase C- $\alpha$-dependent pathway. Diabetes 2008, 57, 460-469. [CrossRef] [PubMed]

59. Wang, X.; Yu, S.; Wang, C.-Y.; Wang, Y.; Liu, H.-X.; Cui, Y.; Zhang, L.-D. Advanced glycation end products induce oxidative stress and mitochondrial dysfunction in SH-SY5Y cells. Vitr. Cell. Dev. Biol.-Anim. 2015, 51, 204-209. [CrossRef]

60. Palsamy, P.; Subramanian, S. Resveratrol protects diabetic kidney by attenuating hyperglycemia-mediated oxidative stress and renal inflammatory cytokines via Nrf2-Keap1 signaling. Biochim. Biophys. Acta (BBA)-Mol. Basis Dis. 2011, 1812, 719-731. [CrossRef]

61. Ruiz, S.; Pergola, P.E.; Zager, R.A.; Vaziri, N.D. Targeting the transcription factor Nrf2 to ameliorate oxidative stress and inflammation in chronic kidney disease. Kidney Int. 2013, 83, 1029-1041. [CrossRef] [PubMed] 